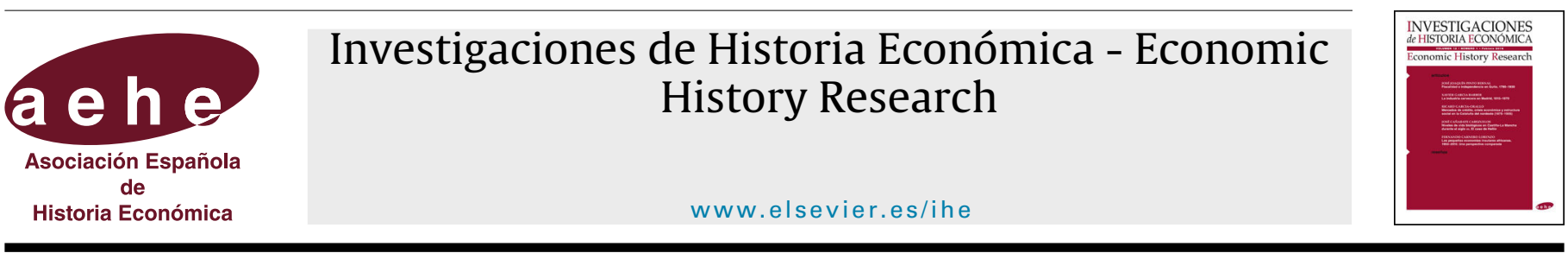

Artículo

\title{
Protoindustria y población en una comarca textil valenciana (1600-1800)
}

\author{
Lluís Torró Gil \\ Departament d'Anàlisi Econòmica Aplicada, Universitat d'Alacant, Sant Vicent del Raspeig, Alicante, España
}

\section{INFORMACIÓN DEL ARTÍCULO}

\section{Historia del artículo:}

Recibido el 8 de febrero de 2017

Aceptado el 23 de mayo de 2017

On-line el 5 de septiembre de 2017

\section{Códigos JEL:}

N33

N63

J12

J13

\section{Palabras clave:}

Protoindustrialización

Demografía

Fertilidad

Nupcialidad

\begin{abstract}
R E S U M E N
La teoría de la protoindustrialización, originalmente, puso en relación el desarrollo de la industria rural con una serie de alteraciones en los patrones de comportamiento demográfico. Salvo excepciones, en España no se han estudiado dichos cambios en las áreas protoindustriales. Disponemos de contribuciones que analizan algunos factores poblacionales en relación con la actividad manufacturera, pero en ningún caso se ha llevado el análisis al terreno de la constatación del conjunto de hipótesis derivadas de las teorías de la protoindustrialización. El presente trabajo se centra en la verificación de algunas de esas hipótesis. La cuestión se aborda desde el estudio de un caso local relevante: la comarca textil valenciana de Alcoi. Utilizando el método agregativo, se analizan los cambios en la fecundidad y la nupcialidad para comprobar si se ajustan a los que Mendels, Medick y otros atribuyen a la demografía de las áreas protoindustriales.
\end{abstract}

(C) 2017 Asociación Española de Historia Económica. Publicado por Elsevier España, S.L.U. Todos los derechos reservados.

\section{Protoindustry and population in a Valencian textile area (1600-1800)}

\section{A B S T R A C T}

Proto-industrialisation theory originally combined the development of rural industry with a set of changes in demographic behaviour patterns. In Spain, with some exceptions, these changes have not been studied in the proto-industrial areas. There are contributions that analyse some population factors regarding the manufacturing activity, but in no case the analysis has been directed towards finding the set of hypotheses derived from the proto-industrialisation theories. The present work focuses on the verification of some of these assumptions. The issue is approached from the study of a relevant local case: the Valencian textile region of Alcoi. Using the aggregative method, an analysis is made of the changes in fertility and marriage to check whether they conform to those that Mendel, Medick and others attribute to the demographics of the proto-industrial areas.

(c) 2017 Asociación Española de Historia Económica. Published by Elsevier España, S.L.U. All rights reserved.
Uno de los elementos centrales -y sin duda también de los más polémicos- de las diversas teorías sobre la protoindustrialización ${ }^{1}$ es el referido a sus efectos sobre los patrones demográficos ${ }^{2}$. Según
F. Mendels $(1984)^{3}$, la consolidación de la protoindustria en una región comportaba la ruptura de la premisa maltusiana del progresivo retraso en la edad del matrimonio al compás del crecimiento

\footnotetext{
Correo electrónico: 1ltorro@ua.es

1 Tomo la expresión "teorías» (en lugar de "teoría») de Ogilvie y Cerman (Ogilvie, 1996).

2 Probablemente la primera constatación de este fenómeno sea el estudio clásico de Chambers (1957) sobre la región del Vale of Trent durante el siglo xviII. Para la
}

polémica referida a las hipótesis demográficas de la protoindustrialización, a pesar del tiempo transcurrido sigue resultando particularmente útil Knotter (2001).

3 En respuesta a la crítica de Vandenbroeke (1984), reiterada en Vandenbroeke (1996). 
de la población. Este fenómeno, causado fundamentalmente por los efectos del incremento de los precios agrarios y de la renta de la tierra $^{4}$, ha sido considerado como uno de los principales mecanismos autorreguladores del sistema demográfico europeo durante la época feudal. A partir de las hipótesis de Mendels apoyadas en los análisis de Alexander V. Chayanov (1974), Hans Medick ${ }^{5}$ expuso las líneas del "patrón» demográfico protoindustrial, que se resumen en cinco rasgos esenciales (Medick, 1976, pp. 301-315; Kriedte et al., 1986, pp. 125-141). El primero de ellos es el incremento de la fertilidad debido a un aumento de la duración de los matrimonios. Este fenómeno estaría vinculado, por un lado, con el elemento crucial del patrón: el descenso secular de la edad al matrimonio en las mujeres y los hombres - pudiendo afectar, a diferencia del patrón agrario, a los dos sexos o solo a uno-, que aumenta la fecundidad y reduce los plazos de reemplazo de una generación por otra. De la misma manera, el incremento en la fertilidad se vería estimulado por un descenso en la mortalidad adulta, contrarrestada por un aumento de la mortalidad infantil. Por otro lado, se produciría una progresiva desvinculación del ritmo de los nacimientos del ciclo agrario, atenuándose la diferencia entre el invierno y el verano. Por último, se daría una creciente elasticidad de las variables demográficas frente a la crise de type ancien, es decir, un incremento de los precios de los cereales provocaría un menor descenso de la natalidad en una localidad protoindustrial que en una agraria. Todo ello derivaba de la lógica del llamado «sistema demoeconómico protoindustrial» que forzaba un comportamiento maltusiano de las familias trabajadoras ${ }^{6}$.

Las investigaciones que todas estas hipótesis han suscitado muestran claramente que es muy difícil establecer un patrón único, válido para todas las áreas y localidades protoindustriales de Europa ${ }^{7}$, como han reconocido los autores que las propusieron (Kriedte et al., 1993, 1996). La tendencia a una mayor fecundidad que parece observarse entre las familias que se dedicaban al trabajo manufacturero no siempre se traducía en un incremento de la población en los términos que proponía el modelo. En general,

\footnotetext{
${ }^{4}$ Aunque no en exclusiva, puesto que las limitaciones legales y consuetudinarias también influirían (Wrigley, 1985, pp. 118-119).

${ }^{5}$ Una presentación resumida de lo que sigue en Medick (1976), expresada en gran medida como crítica a las formulaciones de Laslett sobre la familia (véase Laslett y Wall, 1972, y Laslett, 1987). También destacan las aportaciones de David Levine, tanto en sus investigaciones concretas sobre Shepshed (Levine, 1976) o sobre Terling (Wrightson y Levine, 1995), como en sus obras más generales (Levine, 1977, 1987, 1996). Para una visión general alternativa a las ideas de Laslett y el Grupo de Cambridge, véase Seccombe (1992). Para una alternativa neoclásica basada en el análisis de la productividad marginal del trabajo, véase Pfister (1992).

${ }^{6}$ Puesto que el objetivo de la familia era aumentar lo que Chayanov denominaba la "renta total en trabajo», la vía más eficiente para lograrlo era incrementar el número de hijos. La precocidad nupcial ayudaba a superar rápidamente la fase crítica que se producía entre el nacimiento del primer hijo y el momento en que se ponía a trabajar. Según el modelo, aunque condicionado por la coyuntura salarial, este comportamiento la seguía de lejos: a veces, un empeoramiento de los salarios no suponía un retroceso poblacional. La racionalidad del comportamiento reproductivo de la célula de producción - la familia-, que hizo posible su mantenimiento dentro de los límites de la pobreza, se manifestaba como un comportamiento maltusiano de la oferta de mano de obra en el plano macroeconómico (Kriedte et al., 1986, pp. 114125). Para el planteamiento original chayanoviano sobre el tamaño de la familia y el balance trabajo-consumo, véase Chayanov (1974, pp. 51-58); para el concepto de "renta total en trabajo" y la idea de autoexplotación de la familia campesina, véase Chayanov (1974, pp. 85-95). Un análisis crítico de las teorías de Chayanov centrado en la presunción del modelo de "la virtual ausencia de un mercado de trabajo» en Harrison (1981, cita en p. 159).

7 Un ejemplo de análisis regional exhaustivo se puede ver en Ogilvie (1997, pp. 225-307). Las discusiones se centran en la caída de la edad al matrimonio, la fertilidad intramatrimonial - ¿en auge?, ¿perseguida conscientemente?, ¿resultado de variaciones del período de amamantamiento?...-. el comportamiento de la mortalidad y sus efectos, y, finalmente, el papel de los movimientos migratorios (Marfany, 2006; Marfany, 2010, pp. 959-968). Una extensa bibliografía sobre la cuestión hasta finales del siglo xx en Hudson y King (2000, pp. 708-710). Para un breve balance más reciente, véase Ogilvie (2008). Entre las investigaciones que demuestran la validez de algunas de las hipótesis del modelo, véase Goose (2008).
}

la mayor presión demográfica de unas áreas frente a otras podía depender, en cambio, del mayor o menor grado de proletarización de su población, del tipo de agricultura que se practicaba, o de otros factores como las estrategias hereditarias. Así, por ejemplo, en regiones en las que un determinado comportamiento familiar implicaba la corresidencia de padres e hijos casados, la extensión del trabajo manufacturero no se traducía en un fuerte aumento de la población.

En España no se han llevado a cabo estudios en profundidad sobre los cambios demográficos en las áreas protoindustriales, a excepción del caso catalán ${ }^{8}$. Disponemos de contribuciones que analizan algunos factores poblacionales en relación con la actividad manufacturera, pero en ningún caso se ha llevado el análisis al terreno de la constatación del conjunto de hipótesis derivadas de las teorías de la protoindustrialización ${ }^{9}$. El presente trabajo, a diferencia de otras aportaciones, pretende centrarse en la verificación de algunas de esas hipótesis. Para abordar la cuestión, nos acercaremos a un caso local relevante: la comarca textil valenciana de Alcoi. A lo largo de la Edad Moderna, y particularmente durante el siglo XVIII, este territorio conoció un crecimiento muy intenso de su población, a un ritmo superior a las ya de por sí elevadas tasas valencianas (tabla 1). Este intenso auge demográfico, que tuvo su epicentro en la propia villa de Alcoi, se encuentra claramente relacionado con el desarrollo manufacturero de la zona y la progresiva extensión de la actividad pañera en un red jerarquizada de núcleos que llegó a implicar a 42 poblaciones a principios del siglo XIX (Pérez Planelles, 1807 , p. 21$)^{10}$. Durante el período considerado (Torró, 2000, pp. 43 y 55), Alcoi pasó de cifras de alrededor de un millar de vecinos antes de la expulsión de los moriscos a menos de 800 a mediados del siglo XVII (1646). Tras una recuperación solo interrumpida por la guerra de Sucesión, que situaría su población a un nivel equiparable al de finales del siglo xvi, la villa conoció una evolución que merece sin duda alguna el calificativo de proceso de urbanización (tabla 1).

Lo que aquí se intenta es, por lo tanto, una primera aproximación que indaga hasta qué punto pudo influir la manufactura en esta especial evolución demográfica centrándose, a partir del método agregativo, en dos de las variables más importantes del patrón descrito: la fecundidad y la nupcialidad. El uso de esta metodología presenta claras desventajas a la hora de abordar estas cuestiones. Por esta razón, las conclusiones a las que se llega tienen aún un carácter provisional. El primer aspecto se estudia a partir de la información sobre bautismos y matrimonios que proporcionan los registros parroquiales, mientras que para el segundo se utilizan los censos de población del siglo xviII. El principal inconveniente reside en que no se conservan registros parroquiales del principal núcleo de población, Alcoi, para antes de 1847. La documentación de la única parroquia de esta villa hasta la primera mitad del siglo xIX, Santa María, fue destruida durante la guerra civil. Las parroquias utilizadas en la agregación son las siguientes: Agres (Santacreu, 1985); Almudaina-Benialfaquí, Benimarfull-Benillup, Millena, Gorga y Penàguila (Beneito, 1993); Alcosser, Alcúdia, Santa Maria de Cocentaina, el Salvador de Cocentaina y Gaianes -cuya información me fue proporcionada por Primitivo J. Pla-, y Biar

\footnotetext{
8 Y ni siquiera en este territorio, dejando aparte el excepcional trabajo de Marfany (2012, esp. pp. 93-117), contamos con estudios extensos que tomen como referencia el marco teórico esbozado por Mendels, Medick, etc. Únicamente resultan destacables el de Torrents (1993) sobre Sant Pere de Riudebitlles y el análisis sobre la edad del matrimonio en la Cataluña central de Ferrer et al. (1992).

9 Los trabajos que se han ocupado de la cuestión se han centrado en poner en relación la evolución de los efectivos demográficos con la coyuntura manufacturera. Destacan, sobre todo, García Sanz (1991), Benaul (1991, pp. 227-309), Ros (1999, pp. 21-37), Hernández (2003, pp. 75-92) y Hernández (2008).

10 Un primer análisis en Aracil y García Bonafé (1974, pp. 111-127). Véase también Vallès (1986, pp. 41-90).
} 
Tabla 1

La población de la comarca de Alcoi durante el siglo xviII (l'Alcoià, el Comtat, la Foia de Castalla y Bocairent; 1712-1842)

\begin{tabular}{|c|c|c|c|c|c|}
\hline & $1712-1713$ & 1754 & 1768 & 1786 & 1842 \\
\hline País Valenciano & 410.000 & & 742.000 & 817.000 & 1.089 .000 \\
\hline Tasa anual de crecimiento & & & $1,06 \%$ & $0,54 \%$ & $0,51 \%$ \\
\hline Alcoi & 3.778 & 7.744 & 9.207 & 11.434 & 25.315 \\
\hline Tasa anual de crecimiento & & $1,72 \%$ & $1,6 \%$ & $1,21 \%$ & $1,43 \%$ \\
\hline TOTAL COMARCA & 22.894 & 36.406 & 41.984 & 49.999 & 77.140 \\
\hline Tasa anual de crecimiento & & $1,11 \%$ & $1,09 \%$ & $0,97 \%$ & $0,78 \%$ \\
\hline CoMARca (sin Alcoi) & 19.116 & 28.662 & 32.777 & 38.565 & 51.825 \\
\hline Tasa anual de crecimiento & & $0,97 \%$ & $0,97 \%$ & $0,91 \%$ & $0,53 \%$ \\
\hline
\end{tabular}

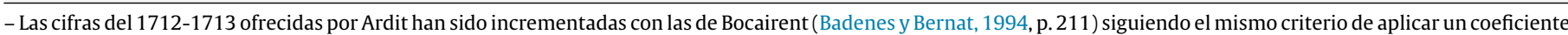
de 4,1 habitantes por vecino y corrigiendo el resultado con un incremento de un $25,4 \%$.

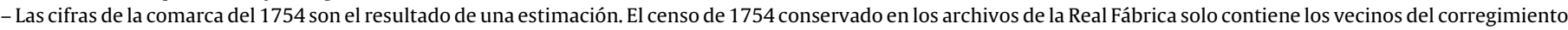

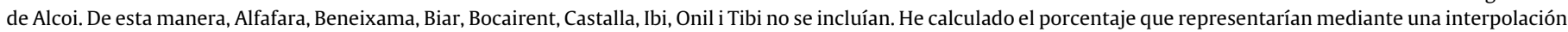
lineal entre la estimación del 1712-1713 y el censo de 1764. La proporción resultante ha sido del 36,14\%.

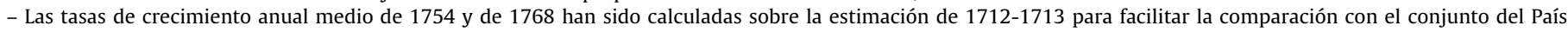
Valenciano.

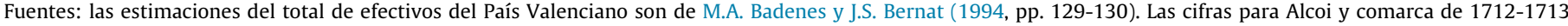

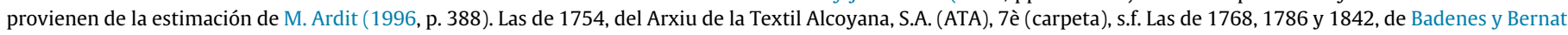
(1994, pp. 246-248, 264-266 y 342-343).

\section{Bautismos agregados}

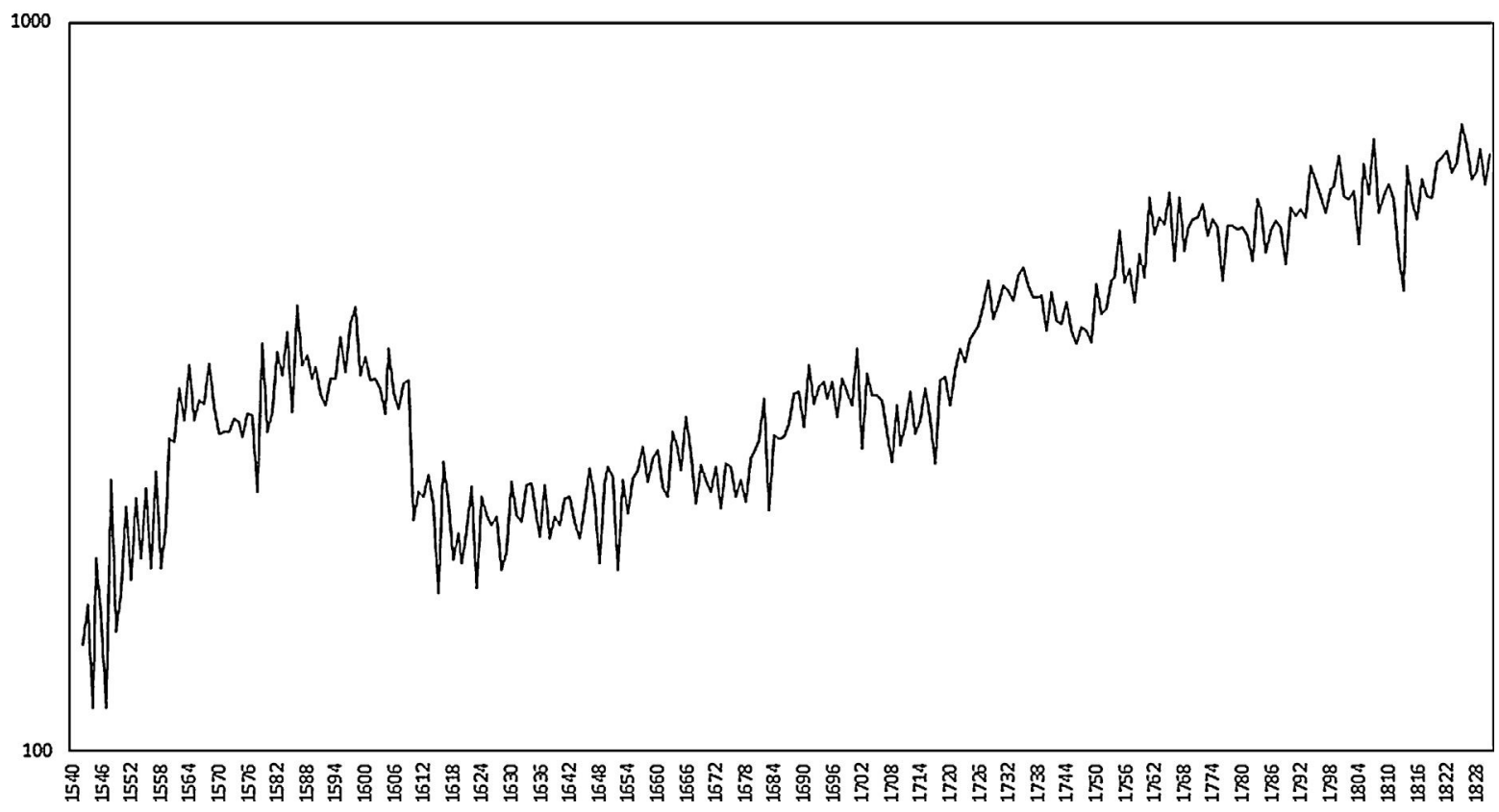

Figura 1. Bautismos agregados.

-cedida por el malogrado Manuel Ardit- ${ }^{11}$. Los datos de bautismos se pueden ver en la figura 1.

Es necesario delimitar con claridad qué es lo que pretendo estudiar. Es evidente que, aunque los efectos de la presencia de una intensa actividad protoindustrial debían sentirse en todos los rincones de la comarca, e incluso más allá, los comportamientos demográficos serían diferentes según el grado de implicación en el trabajo manufacturero de cada localidad. Dado que no existen fuentes generales sobre la ocupación en toda la zona ${ }^{12}$, he recurrido a la información que proporciona la obra de Cavanilles (1797,

\footnotetext{
11 La serie de nupcialidad presenta dos deficiencias. La primera resulta de no haber contado con los matrimonios de Gorga -que sí se incluye en la serie de bautismos-, puesto que estos datos eran demasiado recientes lo que hacía imposible establecer una base de ponderación con series que disponían de registros más antiguos. Dado que los bautismos de Gorga representan en la ponderación un 4,55 \%, este es el margen de sub-valoración de la serie de matrimonios. Además los matrimonios presentan sub-registros antes de 1615.

${ }^{12}$ Lo que más se asemeja a esto es la información del censo de Floridablanca, que, sin embargo, ofrece escasa confianza. De todos modos, la he usado para aproximarme
}

pp. 117-139, 153-184, 192-199 y 203-206) (véase el mapa de la fig. 2). Los datos que se desprenden de ella serán un punto de referencia constante, especialmente a la hora de escoger las parroquias que sirven de muestra para la comprobación de aspectos concretos. Asimismo, es necesario tener en cuenta que la parte oriental de la comarca -al este del eje Alcoi-Cocentaina- fue zona de poblamiento morisco hasta 1609, con la excepción de las parroquias de Penàguila, Gorga y Planes. Previamente, dibujaré los rasgos de la evolución de la pañería desde sus orígenes, deteniéndome, particularmente, en la expansión de la manufactura dispersa desde el segundo cuarto del siglo XVIII.

\section{Protoindustria}

Los orígenes de la pañería en las comarcas de interior del sur del País Valenciano datan de principios del siglo xIV. Sus condiciones

a la correlación entre la actividad industrial y la edad al matrimonio. Un primer intento en Torró (1994). 


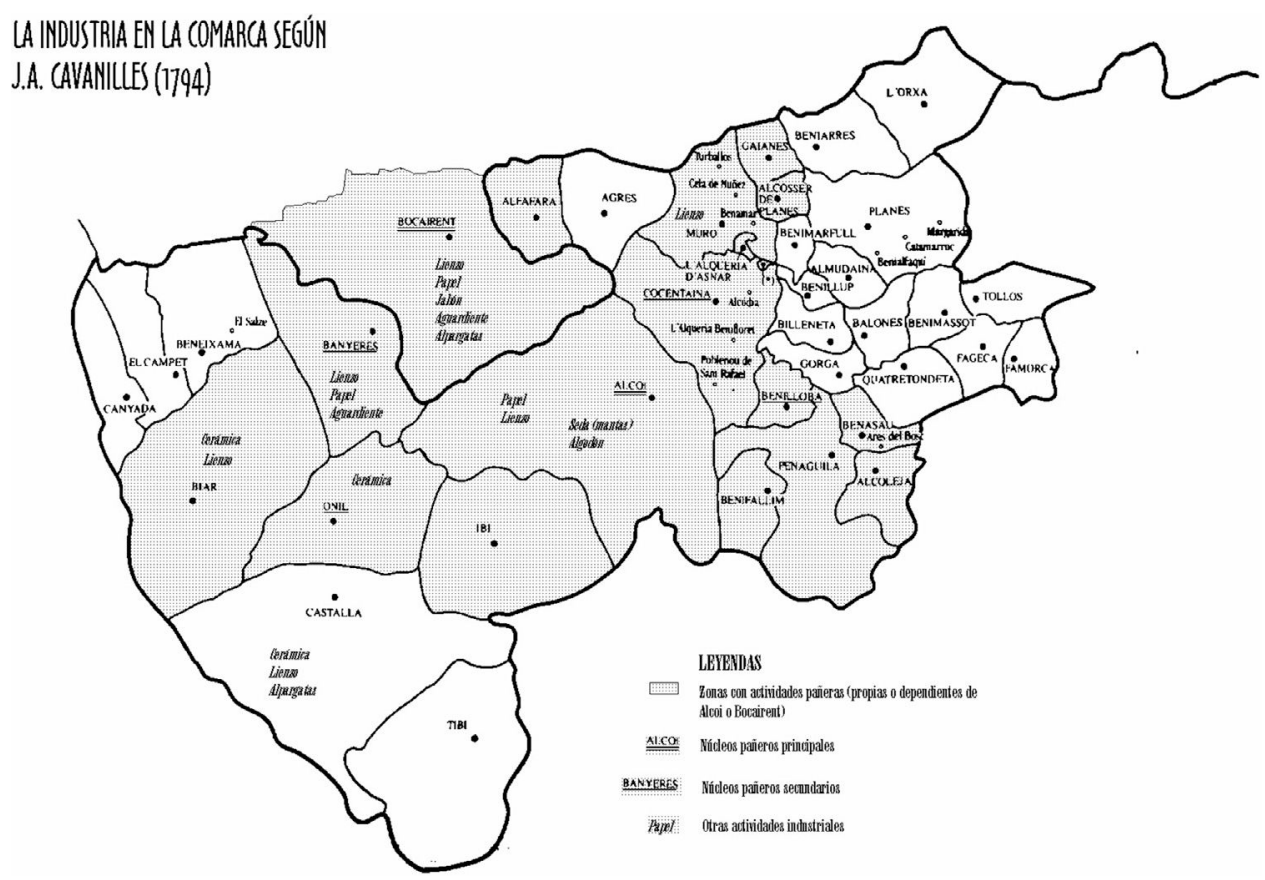

Figura 2. La industria en la comarca según Antonio José de Cavanilles (1794).

físicas eran especialmente adecuadas: abundancia de materia prima y cursos de agua capaces de mover batanes y de abastecer a los tintes. Además, la estructura agraria, caracterizada por una precoz tendencia a la concentración de la propiedad de la tierra, suministró mano de obra excedente para ser empleada en las tareas artesanales, especialmente en algunos núcleos como el que acabará siendo el eje de la actividad manufacturera, Alcoi. Al despuntar de la Edad Moderna se iniciará un fuerte despegue de la pañería. Su temprana estructuración gremial -finales del xv y principios del xvi (Torró, 1996a, pp. xxIx-Xxx; Terol, 2002, p. 60)-y el intenso crecimiento que experimentará hasta las últimas décadas del Quinientos son un buen indicio de su vigor. Desde este momento se inició un cambio de coyuntura con una crisis relativamente intensa que provocó una adaptación desigual de los distintos centros de la zona. El desplazamiento de la demanda hacia tejidos más baratos provocó una fuerte crisis gremial y una importante caída de la producción. La respuesta, decantándose hacia la elaboración de géneros propios de las new draperies, acabó por consolidar la posición de Alcoi como principal localidad productora.

La recuperación de la segunda mitad del sigloxvII conducirá, tras la guerra de Sucesión, al crecimiento del siglo xviII que, en el caso alcoyano, puede calificarse, sin ningún género de dudas, de espectacular. La producción, además de diversificarse e incrementar notablemente su calidad, se multiplicó por seis, como mínimo, convirtiendo a Alcoi en el centro productor más importante de España a finales de la centuria. La pañería alcoyana conquistó en este período tres importantes mercados: el interior -con Madrid y Andalucía a la cabeza-, en el que los paños alcoyanos siempre habían tenido alguna presencia; el mercado ultramarino, y la demanda del Estado, con el abastecimiento de tejidos para el ejército. La producción estuvo dirigida por un reducido grupo de pelaires-fabricantes que controlaban un entramado gremial que recibió el apoyo de la monarquía con la concesión del título de Real Fábrica en 1731 (Torró, 1996a, p. LX). Las relaciones de producción se basaron en la salarización, de modo que el control del proceso de elaboración de los paños se hacía mediante el recurso a la entrega a cuenta de las retribuciones salariales, sin que los trabajadores dependientes adquiriesen ningún derecho sobre la materia prima o el producto, aunque parece que sí poseían sus propias herramientas cuando trabajaban lejos de la supervisión de los fabricantes (Torró, 1996b, p. 50).

Debido al intenso crecimiento que experimentó la producción desde la década de 1720 , los fabricantes recurrieron a los brazos de las familias de labradores modestos o jornaleros agrarios necesitados de recursos complementarios. Esta mano de obra rural se concentró en las actividades previas al tejido, esto es, cardado e hilado, aunque únicamente los dos centros más activos -Alcoi y Bocairent- extendieron la actividad a las localidades de sus alrededores $^{13}$. Los testimonios sobre el trabajo rural disperso en la hilatura son constantes desde, al menos, 1743. Sin embargo, no ocurre lo mismo con el cardado. En este caso la preparación de la trama permaneció concentrada en los mismos núcleos pañeros -y en las propias instalaciones de los fabricantes-, mientras que el cardado para la urdimbre sí se extendió por las poblaciones rurales. Del mismo modo, podemos observar una clara división de género en estas actividades, ya que el cardado fue una actividad claramente masculina pero el hilado ocupó a mano de obra femenina, citándose sistemáticamente en las fuentes como una ocupación de «mujeres y niñas» (Torró, 2000, p. 475).

Parece probable que la dureza del régimen señorial implantado en muchos lugares de la zona después de la expulsión de los moriscos ayudó a la extensión del sistema protoindustrial. La intensidad de las exacciones feudales (Cavanilles, 1797, vol. II, pp. 117 y ss.; Torró, 2008) explica parcialmente la necesidad de recursos de labradores pobres y jornaleros. Este grupo creció exponencialmente gracias a la concentración de la propiedad de la tierra (Torró, 2000, pp. 154-181), fuertemente acelerada con el incremento de la renta de la tierra del xviII. Este fenómeno se observa con especial intensidad en Alcoi, y conllevó una importante salarización de las relaciones de producción en la agricultura (Torró, 2000, pp. 178-179). En 1784, solo 410 contribuyentes de un total de 2.693 -apenas un $15 \%$ - eran propietarios de tierras (Aracil y García

\footnotetext{
13 En cambio, otros centros próximos menos destacados, como Ontinyent o Enguera, no conocieron - por incapacidad o por no necesitarlo por las características de su actividad- una dispersión semejante (Yanini, 1977; Hernández Marco, 1980; Bernabeu y Llin, 1982; Vallès, 1986; Deasit y Seró, 1989).
} 
Cocientes matrimoniales (1571-1829)

agregación (11 parroquias)

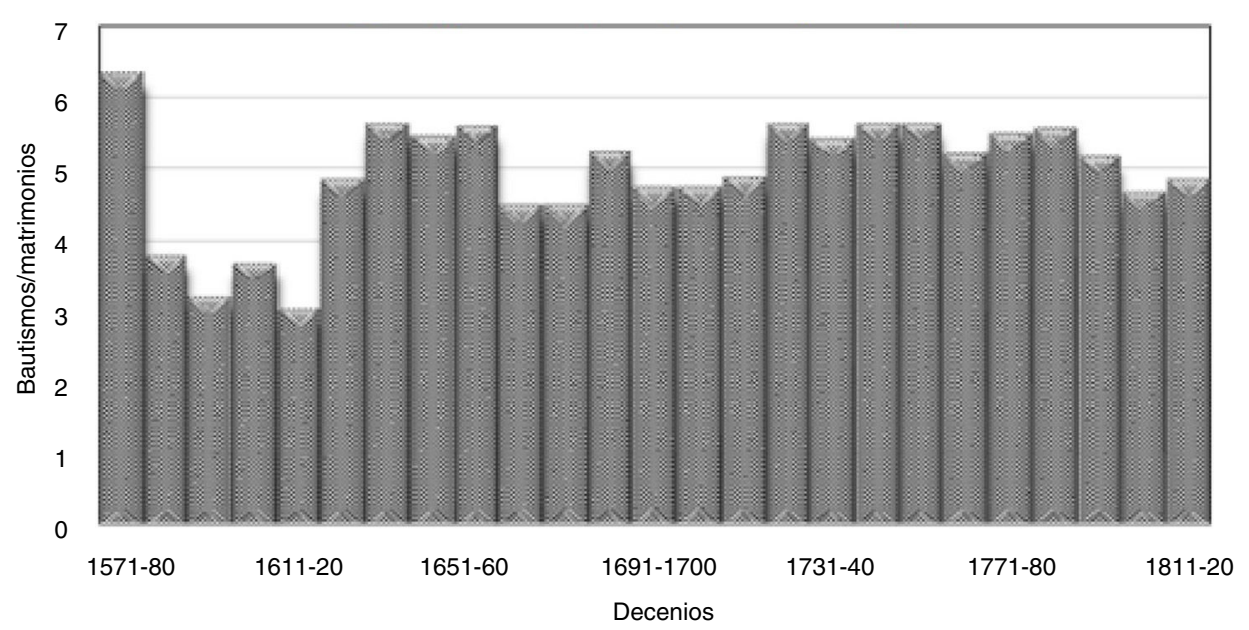

Figura 3. Cocientes matrimoniales (1571-1829).

Bonafé, 1974, pp. 67-85). A principios del siglo XIX (1807), cuando la población activa agraria se había reducido al 35\% del total, únicamente el $20 \%$ de los activos agrarios cultivaban tierras propias, el $32 \%$ tierras ajenas -fundamentalmente en régimen de aparceríay el restante $48 \%$ serían asalariados. Del mismo modo, en una gradación que dependería, entre otras cosas, del volumen de población, el resto de la comarca también conoció procesos similares. Así pues, la expansión manufacturera de localidades como Alcoi o Bocairent, particularmente, encontró el terreno abonado para la extensión del trabajo a domicilio en labores de baja calificación.

\section{Fecundidad}

Una de las variables recurrentes en la explicación de la vitalidad demográfica valenciana desde la primera mitad del siglo XVII ha sido la elevada fecundidad. Según las estimaciones más aceptadas (Ardit, 1993, pp. 60-62), su tasa se situaría entre el 380 y el 400\%. La descendencia real, no obstante, dependía de la edad al matrimonio y de la mortalidad, que afectaba a la duración de las uniones. De este modo, aunque la baja edad al matrimonio de las mujeres -situada entre los 21 y los 23 años- proporcionaría teóricamente unos 8 hijos por familia, en la práctica los valores se situaron alrededor de los 5 . Las desviaciones que se producían respecto a estos valores medios aceleraban o retrasaban el ritmo de crecimiento.

La única forma de estudiar la fecundidad mediante el método agregativo es la que se deriva del cálculo de los cocientes matrimoniales. Se trata de un indicador grosero que sirve, al menos, para aproximarse a su evolución. Los cálculos se encuentran resumidos en la figura 3. La evolución general se presenta bastante ajustada a los resultados que en su día obtuvieron Pérez García y Ardit (1988) ${ }^{14}$ en su trabajo para el conjunto valenciano, lo cual confirma su pertinencia. No obstante, también se aprecian algunas diferencias que conviene subrayar.

Obviando el período anterior a la expulsión de los moriscos -con resultados marcados por distorsiones en la muestra ${ }^{15}$ y por la existencia de dos comunidades que mantienen comportamientos demoeconómicos muy distintos ${ }^{16}-$, la cifra inmediatamente

\footnotetext{
14 He utilizado el mismo método.

15 Véase supra.

${ }^{16}$ Las diferencias entre el comportamiento demográfico de cristianos viejos y moriscos fue constatada en su día por James Casey (1981, pp. 25-32) en su estudio sobre las parroquias valencianas de Pedralba y Bugarra. Esta mayor fecundidad,
}

posterior (1611-1620) marca el mínimo de la serie con un bajísimo cociente de 3,04 bautismos por matrimonio. Esta situación refleja, sin duda, las dificultades de la repoblación de los lugares abandonados a causa de la expulsión ${ }^{17}$ y la intensidad de los movimientos migratorios en la zona, constatada por Pla (1988). De la misma manera, la fuerte recuperación en el decenio 1621-1630 indicaría una tendencia clara a la estabilización del poblamiento. Hasta aquí, aunque la intensidad de las oscilaciones es mayor en este caso, el panorama es prácticamente idéntico al del conjunto del país. Sin embargo, la situación que se observa en el período 1631-1640 contrasta notablemente: mientras que el País Valenciano alcanza el cociente más bajo del período comprendido entre 1600 y 1840 (Pérez García y Ardit, 1988, p. 217), la comarca continúa la recuperación, estabilizándose en torno a los 5,5 bautismos por matrimonio - muy superior a los valores de 4,5 que se constatan para el conjunto valenciano- a lo largo de tres décadas completas. Este nivel no se recuperará hasta la década de los treinta del siglo xviII. Del mismo modo, resulta extraña la caída posterior, aunque, ciertamente, a partir de la década de los sesenta -y con alguna variación coyuntural que sigue sin coincidir con las que se observan globalmente- el crecimiento será constante hasta la década de los cincuenta del siglo XVIII.

No deja de sorprender que el segundo cuarto del sigloxvII muestre, a la vez, unos elevados cocientes matrimoniales y un estancamiento poblacional (véase fig. 3). Esta circunstancia es atribuible a la elevada mortalidad y a la baja nupcialidad. Además, cabe pensar, particularmente, en una especial incidencia de la mortalidad infantil. De los datos que aporta Pla (1991, p. 22) se deduce que esta variable fue mayor en la primera mitad del siglo xvir que en la segunda. A partir de 1650 disminuiría la mortalidad infantil y aumentaría la nupcialidad, lo cual explica la recuperación demográfica con cocientes bajos. El hecho determinante, no obstante, es el impacto de la mortalidad sobre la duración de los matrimonios.

asentada sobre una precoz nupcialidad, se constata también en otros estudios (Ardit, 1993, pp. 23-28) y podría explicarse por la corresidencia de parientes casados, un rasgo propio de la sociedad andalusí (Guichard, 1976; Zomeño, 2011) que perdura entre los moriscos valencianos probablemente hasta su expulsión en 1609 (Ardit, 2004, p. 42; Torró Abad, 2009).

17 Los lugares habitados por moriscos -situados al este del eje Alcoi-Cocentaina; véase el mapa de la fig. 2 - supondrían un 35\% de la población total de la comarca. Una cifra muy próxima a las estimaciones para el conjunto del País Valenciano (Pérez García y Ardit, 1988). 
En el caso de Penàguila - única parroquia de la que disponemos de datos-el porcentaje de segundas nupcias pasó de un bajísimo $13 \%$ entre 1594 y 1631 al $20 \%$ entre 1650 y $1699^{18}$.

La importante caída de los cocientes en la segunda mitad del XVII, además de las razones ya aducidas, se encuentra claramente condicionada por el peso de las localidades no repobladas. A partir de aquí, el perfil del conjunto es de recuperación hasta la década de los veinte del siglo xviII. Mientras que el descenso de los años sesenta no es general, el que se produce entre los noventa y principios del XviII, sí lo es. Aunque es probable que en este comportamiento influyeran los efectos de la guerra de Sucesión, existen razones que invitan a sospechar que el fenómeno no dependió tan solo de este hecho. A partir de aquí, el perfil del conjunto es de recuperación hasta la década de los veinte del siglo XviII. Desde la década de 1730 los cocientes se situarán por encima del 5 y se mantendrán con leves oscilaciones hasta la década de los ochenta. Solo en el último decenio del siglo xviII se detecta una clara tendencia a la baja que llevará a los cocientes a situarse por debajo del 5 en el primer cuarto del siglo xIX. De nuevo, la evolución de la mortalidad ayuda a comprender esta evolución. Los indicios apuntan a un crecimiento de la mortalidad desde finales del siglo XVII (Pla, 1986, p. 62). Si nos fijamos en lo ocurrido en el conjunto valenciano, tras la grave crisis de la guerra de Sucesión, la mortalidad disminuiría hasta 1770 , para luego repuntar, suavemente primero y con mayor intensidad a principios del XIX (Badenes y Bernat, 1991, pp. 40-41). Este comportamiento concuerda con la evolución que muestra el porcentaje de segundas nupcias en Penàguila: un descenso al 18,1\% en la primera mitad del sigloxviII y al $13,3 \%$ en su segunda mitad -claro resultado de una menor incidencia de la mortalidad adulta-, para volver a aumentar en los primeros cincuenta años del siglo xıx hasta el 15,6\% (Beneito, 1986, p. 167). La tendencia se vería compensada por un aumento de la mortalidad infantil que se acentuaría en la segunda mitad del XVIII (Pla, 1986, p. 63) ${ }^{19}$.

\section{Nupcialidad}

Los elevados cocientes matrimoniales detectados ${ }^{20}$ deben explicarse, básicamente, a partir de los patrones de nupcialidad y de mortalidad. Como ya he apuntado algo sobre la influencia de la segunda sobre la primera, me ocuparé ahora estrictamente de la variable clave según los modelos propuestos por Mendels y Medick: la edad al primer matrimonio. Ya he señalado que el País Valenciano moderno se caracterizó por una marcada tendencia a la precocidad nupcial. En la zona más próxima a la comarca estudiada siguiendo el método de reconstrucción de familias, la Vall de Guadalest ${ }^{21}$, en el siglo XVII las mujeres se casarían en promedio a los 22 años y 10 meses y los hombres a los 27 años y 11 meses (Pla, 1986, p. 52 $)^{22}$. En estas condiciones resulta difícil detectar una tendencia a la baja en la edad al matrimonio - al menos por lo que respecta a las mujeres-, tal y como presuponen los modelos mencionados. Y mucho menos cuando faltan estudios de reconstrucción de familias que nos proporcionarían una idea precisa sobre la cuestión. Con todo, la existencia de los censos de Aranda de 1768 (Ardit

\footnotetext{
18 El porcentaje de $1594-1631$ es tan bajo que hay que esperar al período entre 1900 y 1939 para volver a hallar un valor inferior (Beneito, 1986, p. 167).

${ }^{19}$ Se pueden contrastar estas tendencias con lo observado para la ciudad de Igualada por Marfany (2005).

20 Son claramente superiores, por ejemplo, a los de la contigua Marina Alta (Cuevas, 1991, p. 79) o a los del conjunto valenciano (Pérez García y Ardit, 1988, p. 217). La media del siglo XviII se sitúa aquí por encima del 5,3, mientras que la de la Marina Alta se queda en el 5,02 y la del País Valenciano, en el 4,8.

${ }^{21}$ En el ámbito de influencia comercial de Alcoi durante todo el período y dentro de su corregimiento en el siglo xviII.

22 Según los cálculos de este mismo autor (Pla, 1983, p. 101), a lo largo del siglo XVII la edad al matrimonio de las mujeres habría disminuido durante el primer tercio para tender lentamente al alza con posterioridad.
}

et al., 2001, pp. 143-184) ${ }^{23}$ y de Floridablanca de 1786 (Castelló, $1976)^{24}$, con una clasificación por estado civil y por edades, permite que se pueda ensayar alguna aproximación.

Lo primero a tener en cuenta es que los datos de ambos censos no son homogéneos. Para la cuestión que nos ocupa, el censo de Aranda no especifica los viudos en cada tramo de edad, asimilándolos - presumiblemente- a los solteros. Esto hace inviable el cálculo aproximado de la edad al matrimonio, que sí permite, en cambio, el censo de Floridablanca al distinguir claramente a los viudos. Así pues, en primer lugar he definido algunos indicadores sobre la actividad manufacturera en la comarca para, una vez calculada la edad al matrimonio según los datos de $1786^{25}$, analizar sus correlaciones. En segundo lugar, he calculado el porcentaje de casados en los primeros tramos de edad en los censos de Aranda y de Floridablanca para inferir la tendencia que se observa entre ambas fechas por lo que respecta al matrimonio temprano ${ }^{26}$. He desestimado analizar el porcentaje de celibato definitivo ${ }^{27}$ puesto que los datos que se obtienen parecen estar más correlacionados con el tamaño de la población -y la consiguiente presencia de órdenes religiosas-que con cualquier otro factor. En el caso de Alcoi el porcentaje en 1786 es del 7,5\% para los hombres y del 6,1\% para las mujeres, claramente inferiores a los del conjunto de España -ya sea población rural o urbana-(Pérez Moreda y Reher, 2003, p. 134), pero superiores a los de las pequeñas poblaciones rurales de la comarca - con valores de entre el 3 y el $5 \%$ para los hombres e inferiores al $4 \%$, con frecuencia situados en el $0 \%$, para las mujeres. La media comarcal arroja resultados cercanos a los de Alcoi: 7,3\% para los hombres y 6,3\% para las mujeres. Por último, he comparado el comportamiento de algunos índices de la evolución de los matrimonios con otro de la evolución de la producción pañera de Alcoi.

Aproximarse a la proporción del empleo manufacturero en los pueblos de la zona es un trabajo difícil. La única fuente de alcance general es el propio censo de Floridablanca. No obstante, la diversidad de criterios que parecen haber empleado las distintas autoridades locales a la hora de responder otorga un escaso nivel de confianza a las categorías que en él se expresan, escondiendo normalmente situaciones heterogéneas bajo un mismo calificativo. El caso de los jornaleros es el más significativo, ya que las diferencias en sus proporciones están determinadas por el criterio utilizado, siendo probable que en muchos casos explotasen algún tipo de tierra en propiedad y/o arrendamiento. Esta situación se agrava a la hora de contabilizar los activos manufactureros. Aunque la población activa en este sector debe calificarse globalmente de elevada, las limitaciones del censo provocan que estos datos tengan escasa consistencia. La mejor prueba es que la población activa supondría solo un $28,7 \%$ del total ${ }^{28}$. Debemos suponer, pues, que muchos jornaleros compaginarían la actividad agraria con la industrial ${ }^{29}$,

\footnotetext{
23 El cuaderno de Alcoi ha sido reproducido y analizado por Beneito (1994).

24 Existe un importante estudio demográfico sobre el sur del País Valenciano basado en los datos que proporciona el censo de Floridablanca (Bevià et al., 1987).

25 A partir del método propuesto por Henry (1980, pp. 56-59). El principal sesgo es la dificultad de tomar en consideración los movimientos migratorios, sin duda importantes. Aunque los cálculos ofrecidos por Pérez Moreda y Reher (2003, pp. 125, 127 y 137-138) sobre Alcoi parecen indicar ausencia de migraciones, ello ha de deberse, como ellos mismos indican, a una mortalidad superior a la de las tablas base que utilizan para calcular los saldos migratorios (Pérez Moreda y Reher, 2003, p. 127).

${ }^{26}$ Como hacen Badenes y Bernat (1991, pp. 41-42).

27 Siguiendo el método propuesto por Pérez Moreda y Reher (2003, p. 120) sobre la base de Henry (1980, pp. 55-56).

28 Según las cuentas de Beneito (1993, p. 79), de la cual los activos manufactureros representarían un 23\%. Aunque su denominación más frecuente es la de artesanos (2.215), también aparecen muchos fabricantes (549) y algunos trabajadores de la lana (53).

${ }^{29}$ De hecho, el vecindario de 1820 de Alcoi presenta casos en los que la denominación de jornalero se acompaña con un oficio industrial. Así, tenemos dos jornaleros-cardadores, un jornalero-papelero y un jornalero-tintorero. Aunque su
} 
Tabla 2

Coeficientes de correlación con la edad al matrimonio (l'Alcoià, el Comtat i la Vall d'Albaida)

\begin{tabular}{|c|c|c|c|c|c|}
\hline \multirow[t]{2}{*}{ Comarca } & \multirow[t]{2}{*}{ Índice } & \multicolumn{2}{|c|}{$r$} & \multicolumn{2}{|c|}{$\mathrm{r}^{2}$} \\
\hline & & Mujeres & Hombres & Mujeres & Hombres \\
\hline \multirow[t]{2}{*}{ L'Alcoià } & Jornaleros/activos agrarios & $-0,3442$ & $-0,1924$ & 0,1185 & 0,0370 \\
\hline & Artesanos/total activos & $-0,5364$ & $-0,2955$ & 0,2877 & 0,0873 \\
\hline \multirow[t]{2}{*}{ El Comtat } & Jornaleros/activos agrarios & $-0,0895$ & $-0,0097$ & 0,008 & 0,0001 \\
\hline & Artesanos/total activos & $-0,304$ & $-0,4455$ & 0,092 & 0,198 \\
\hline \multirow[t]{2}{*}{ La Vall d'Albaida } & Jornaleros/activos agrarios & $-0,1674$ & $-0,2349$ & 0,028 & 0,0552 \\
\hline & Artesanos/total activos & $-0,1199$ & $-0,1758$ & 0,0144 & 0,0309 \\
\hline
\end{tabular}

y a la inversa, en las localidades pequeñas en las que la proporción de artesanos es muy elevada, seguramente muchos de ellos se dedicarían parcialmente a la agricultura. Y ello por no hablar de la invisibilidad del empleo femenino, una variable crucial ausente en los $\operatorname{censos}^{30}$. Para calibrar su importancia debemos señalar que un informe de la Real Fábrica de Paños de Alcoi apuntaba que ya en 1743 únicamente dentro de la villa trabajaban unas 2.150 mujeres y niñas en la hilatura doméstica ${ }^{31}$. Más adelante, en 1807 , no solo seguían ocupándose en estos menesteres un mínimo de 2.482 alcoyanas, sino que, además, las féminas representarían la gran mayoría de las «otras 5.500 personas empleadas en la misma industria domiciliadas en 42 pueblos de la comarca» (Pérez Planelles, 1807, p. $10)^{32}$. La ausencia de este empleo femenino es, sin ningún género de dudas, la principal distorsión que debemos afrontar en el análisis.

Dejando aparte la difícil cuestión del trabajo femenino, es necesario, pues, encontrar un indicador que tenga en cuenta estas contingencias. De este modo, he elaborado un índice de activos industriales equivalente al porcentaje que estos representan sobre el total de activos. Como podía dejar fuera alguna localidad con importantes actividades manufactureras ${ }^{33}$, ha calculado también un índice de los jornaleros sobre el total de la población activa agraria $^{34}$. Con estos índices y las medias de edad extraídas del propio censo he calculado el coeficiente de correlación de Pearson en las comarcas -siguiendo en este caso los criterios de división comarcal de J.E. Castelló- de l'Alcoià (con la Foia de Castalla), el Comtat y la Vall d'Albaida ${ }^{35}$ (tabla 2).

proporción es ínfima, puede constituir la punta del iceberg de un fenómeno generalizado y en auge a lo largo del siglo xviII (Arxiu Municipal d'Alcoi [AMA], I.4.4.7-3.672-5.261: Contribucions-veinari). Para un estudio sobre la pluriactividad en una región protoindustrial y sus efectos demográficos, véase Hendrickx (2003). Algunos análisis sobre esta cuestión en España en Domínguez (1993) y Sarasúa (2000).

30 Sobre el trabajo femenino en la protoindustria destacan Gullickson (1995) y, más recientemente, Ogilvie (2003), Van Zanden (2011) y Martini y Bellavitis (2014).

31 Arxiu de la Textil Alcoyana, S.A. (ATA), 7è (carpeta), 9-V-1753, s.f.

32 El testimonio de Cavanilles es concluyente respecto a la importancia de la ocupación femenina en la actividad textil. En el caso de Ibi, afirma que «los de Ibi preparan lanas para las fábricas de Alcoy y Bocayrént. [...] entran en Ibi cada semana mas de 300 pesos, y se reparten entre la clase que sería pobre, y tal vez infeliz sin este socorro. Con él viven mas de 80 cardadores y 600 hilanderas, mugeres ó niñas». En Benifallim, «las fábricas de Alcoy prestan recursos poderosos [...], cuyas mugeres y niñas se ocupan ventajosamente en hilar lanas». En Benasau, «las mugeres y niñas [...] ganan cada semana hilando lanas mas de 100 pesos». Finalmente --por no seguir multiplicando las citas-, indica que «las mugeres, niñas y algunos hombres [de Benilloba] ganan cada semana 300 pesos en hilar y preparar lanas para las fábricas de Alcoy» (Cavanilles, 1797, II, p. 180, 197, 203 y 204).

33 Basta con aducir el significativo ejemplo de Ibi -véase la nota precedente-, que solo muestra un escaso 7,25\% de población activa artesana en el censo.

34 Suponiendo que un alto porcentaje de jornaleros implicaría una insuficiencia de ingresos procedentes de la agricultura y, en consecuencia, una alta propensión al trabajo complementario en la manufactura.

35 La decisión de incluir a la Vall d'Albaida pretende contar con una muestra más representativa. El hecho de que se trate de una comarca limítrofe - por el norte-que se puede incluir también dentro del área pañera, con localidades tan importantes como Ontinyent, justifica suficientemente su inclusión. Mantener aquí el criterio de división comarcal de Castelló se hace para facilitar la crítica y la comparación. Las
Tabla 3

Medias de edad al matrimonio según un índice de actividad industrial corregido

\begin{tabular}{llcll}
\hline Tramos (\%) & Número de casos & Población & \multicolumn{2}{c}{ Medias de edad(años) } \\
\cline { 3 - 5 } & & & Hombres & Mujeres \\
\hline 0 & 8 & 1.979 & 27,6271 & 25,6307 \\
$0-5$ & 10 & 6.748 & 25,9982 & 23,5171 \\
$5-10$ & 9 & 7.024 & 27,7938 & 24,832 \\
$10-15$ & 9 & 8.009 & 25,6575 & 22,8493 \\
$15-20$ & 5 & 10.202 & 24,4478 & 22,6784 \\
$20-25$ & 5 & 12.205 & 24,2865 & 22,2469 \\
$25-35$ & 5 & 11.336 & 25,1164 & 22,9907 \\
$>35$ & 5 & 22.511 & 23,8134 & 21,4602 \\
Total & $56(83,58 \%)$ & $80.014(95,84 \%)$ & & \\
\hline
\end{tabular}

Los resultados del análisis no son concluyentes dada la baja significación de las $\mathrm{r}^{2}$. A pesar de ello, creo que es relevante que en todos los casos las correlaciones sean negativas; es decir, la edad al matrimonio es menor cuanto mayor es el índice calculado. Tampoco cabe extraer conclusiones respecto al sexo, ya que, mientras que en l'Alcoià resulta evidente que son las mujeres quienes más acusan las correlaciones, en el resto la norma parece más bien la contraria. Para afinar un poco más los cálculos he elaborado una muestra mayor uniendo todos los pueblos de las tres comarcas y calculando un único coeficiente de correlación con un índice de la actividad industrial que lo mide, en este caso, en relación con los activos agrarios ${ }^{36}$. Los resultados también ofrecen una baja significación, con $r^{2}$ de 0,0849 para los hombres y 0,1392 para las mujeres, pero la correlación sigue siendo negativa, con coeficientes de $-0,2914$ y $-0,3731$, respectivamente.

Por último, he calculado las medias de edad entre los diferentes grupos de población según un índice de actividad industrial corregido $^{37}$. Los resultados (tabla 3 ) confirman, como era de esperar, lo que se observa en los cálculos de correlación. En líneas generales, la edad al matrimonio tiende a ser más precoz en las localidades con una mayor presencia de artesanos. Asimismo, hay una clara tendencia al incremento del índice -disminución de la edad, por lo tanto- conforme crece el volumen de la población considerada. Tampoco se observa una clara tendencia a que sea un solo sexo el que manifieste mayor precocidad; por el contrario,

fuentes y los cálculos se pueden consultar en Torró (2000, pp. 620-654). Los cálculos de correlación se han realizado previa expurgación de aquellas localidades que arrojaban resultados sospechosos o claramente aberrantes. La muestra de l'Alcoià alcanza el $100 \%$, mientras que la del Comtat (4 casos expurgados) supone el $84,61 \%$ de las localidades y el 95,24 \% de la población, y la de la Vall d'Albaida (3 casos expurgados), el 84,37 y el $95,15 \%$, respectivamente.

36 Sigo un criterio idéntico al de Enrique Llopis (1993, p. 47). La muestra es más restrictiva al disponer de más casos, expurgándose un total de 18 poblaciones (30,5\%).

37 El índice de actividad industrial corregido expresa el porcentaje de artesanos sobre el total de la población excepto los jornaleros. Se trata de obtener un indicador que, primando la actividad manufacturera, tenga en cuenta, a la vez, el peso de los jornaleros. Además de los pueblos que ya habían sido excluidos de la muestra, he descartado alguno más por sus efectos distorsionadores. El más destacado es Aielo de Malferit, en la Vall d'Albaida, que, con un elevadísimo porcentaje de jornaleros (73,86\%), no incluye, en cambio, ningún artesano, lo cual reduce el índice a 0. 
Tabla 4

Media de edad al matrimonio (1786) en las localidades de l'Alcoià, el Comtat y la Vall d'Albaida agrupados por su dedicación manufacturera, según Cavanilles

\begin{tabular}{llll}
\hline & Población & $\begin{array}{l}\text { Media edad } \\
\text { hombres }\end{array}$ & $\begin{array}{l}\text { Media edad } \\
\text { mujeres }\end{array}$ \\
\hline Lana & $37.115(45,84 \%)$ & 23,8 & 22,072 \\
Lienzo o cáñamo & $9.091(11,23 \%)$ & 25,315 & 22,635 \\
Cerámica & $7.707(9,52 \%)$ & 25,808 & 23,672 \\
Otras & $3.464(4,28 \%)$ & 25,575 & 22,854 \\
Sin manufactura & $23.585(29,13 \%)$ & 25,785 & 23,418 \\
Total & $80.962(96,98 \%)$ & 24,827 & 22,697 \\
\hline
\end{tabular}

Los porcentajes son sobre el conjunto de la muestra, y el del total, sobre la población de las tres comarcas.

Manufactura lanera: 12 localidades (20,69\%): Alcoi, Alcoleja, Alfafara, Banyeres, Benasau, Benifallim, Benilloba, Bocairent, Cocentaina, Ibi, Penàguila, Ontinyent. Manufactura de lienzo: 4 localidades (6,9\%): Atzeneta, Castalla, Muro, l'Olleria. Manufactura de cerámica: 4 localidades (6,9\%): Biar, Castelló de les Gerres, Onil, Ràfol de Salem.

Otras manufacturas: 2 localidades (3,45\%): Albaida (jabón), Salem (nieve). Sin manufactura: 36 localidades $(62,07 \%)$.

los dos ven reducida la edad en proporciones similares, aunque es ligeramente mayor en las mujeres.

Sin embargo, todos estos datos se sostienen sobre una base muy frágil: la distribución ocupacional que ofrece el censo de Floridablanca. Para no supeditar exclusivamente las conclusiones a los índices que se obtienen de él, he intentado una aproximación diferente. En este caso se trata de un indicador cualitativo, las apreciaciones que nos legó el ilustrado Josep Antoni Cavanilles en su viaje por todo el País Valenciano en la primera mitad de la década de los noventa del siglo xviII. Siguiendo sus indicaciones, he dividido la muestra de localidades en 5 grupos diferentes, según su dedicación a la manufactura, y he calculado las medias de edad que se obtienen con los datos del censo de Floridablanca para cada uno de los grupos (tabla 4).

Aunque la clasificación se basa en información fundamentalmente cualitativa, los resultados vuelven a apuntar a una clara tendencia a la precocidad nupcial en las poblaciones más dedicadas a la manufactura. Además, los datos de la tabla 4 permiten establecer algunos matices relevantes. El primero es que es la pañería se asocia con las edades nupciales más bajas, tanto para los hombres como para las mujeres. La presencia, en cambio, de otros sectores textiles, como el cáñamo o el lienzo, ayuda a mantener baja la edad al matrimonio para las mujeres, ligeramente inferior a la media, pero no para los hombres, claramente por encima, aunque manteniendo la segunda posición. Por el contrario, las otras actividades manufactureras más bien entorpecen la nupcialidad, con la excepción de la fabricación de jabón en Albaida ${ }^{38}$. De hecho, las localidades dedicadas a la cerámica muestran edades superiores, incluso, a las de aquellas sin especialización manufacturera. Así pues, solo la manufactura textil, y muy especialmente la pañería, seguramente por su gran dispersión y por la elevada proporción de población ocupada en ella - particularmente femenina-, parece tener claros efectos sobre el fenómeno que nos ocupa. El caso de Alcoi, con su bajísima edad nupcial -22 años para hombres y 20 para mujeres-, es muy representativo ${ }^{39}$.

\footnotetext{
38 El epígrafe de las otras manufacturas refleja dos situaciones claramente opuestas: la de Salem (Vall d'Albaida), con una edad muy tardía, de 30 años para los hombres y 25 para las mujeres, y la de Albaida, con 24 y 22, respectivamente. Sobre la fabricación de jabón en Albaida en los siglos XVIII y XIX -actividad claramente relacionada con la pañería alcoyana durante el Setecientos-, véase Terol (1996).

39 Debe tenerse en cuenta, también, que el peso de la villa de Alcoi en la muestra de localidades pañeras - como en el resto de cálculos- es decisivo, pues supone un $30,81 \%$ del total.
}

Resulta difícil discernir si la baja edad al matrimonio que se observa en las localidades pañeras responde a una tendencia descendente o, por el contrario, a una mayor lentitud en un contexto de progresivo retraso. En la tabla 5 se puede observar la evolución de lo que he llamado índice de precocidad nupcial, que equivale al porcentaje de casados existente en el tramo de edades de entre $16 \mathrm{y}$ 25 años en los censos. Como he señalado antes, puesto que el censo de Aranda no distingue a los viudos de los solteros, esta proporción puede constituir un indicador aproximado de una baja edad al matrimonio ${ }^{40}$. De nuevo la tendencia general parece ser la de un retraso en la edad al primer matrimonio, un poco más acusada para las mujeres ${ }^{41}$. El comportamiento diferencial, además, también se observa en función de la actividad productiva. En 1768 eran las localidades con dedicación textil las que tenían índices más elevados, especialmente para los hombres. En cambio, por lo que respecta a las mujeres, aunque la tendencia también está presente, en conjunto aparece como menos acusada, manteniéndose las medias de los 5 tipos de localidades muy próximas a la general. Por último, las localidades con actividades industriales no textiles tienen valores por debajo no solo de la media, sino incluso de las localidades sin actividad manufacturera. Esto ratifica la relación entre la baja edad al matrimonio y la manufactura textil.

Dieciocho años más tarde, aunque las medias globales no muestran cambios radicales, la situación entre los diferentes grupos ha variado sustancialmente. Mientras que las localidades pañeras mantienen índices elevados, con una tendencia clara aunque no muy pronunciada al matrimonio cada vez más precoz, en el resto la situación es la opuesta. Los hombres se casan cada vez más tardíamente pero, en términos comparativos, son las mujeres las que experimentan el retraso con mayor intensidad. Con dos excepciones: Albaida, con su industria jabonera, donde los hombres se casan mucho antes en 1786 que en 1768, y las localidades lenceras, en las que, aunque el retraso se manifiesta en los dos sexos, es muy intenso para los hombres, mientras que las mujeres mantienen una temprana edad nupcial. La tendencia en el caso de las localidades dedicadas a la manufactura de la lana es especialmente significativa, puesto que va en contra de la tendencia general del País Valenciano, que pasó del 36,6 al 31,3\% de mujeres casadas entre 16 y 25 años (Badenes y Bernat, 1991, p. 42).

El no disponer de más puntos de comparación no nos permite ir más allá. Las limitaciones documentales pesan decisivamente, puesto que la distancia temporal que separa ambos censos es demasiado breve como para que se puedan distinguir tendencias con claridad. Además, el momento de su elaboración se enmarca en una coyuntura de clara reducción de la nupcialidad (fig. 4). Por ello, los comportamientos contra la tendencia general adquieren una relevancia especial. Con el objeto de ampliar el período de observación disponemos, para inicios del siglo xIX, de los datos del interrogatorio de 1804 para Alcoi y de noticias fiables sobre la villa de Penàguila, desde 1838. La edad media al matrimonio que se desprende de los datos de Alcoi de 1804 es de 21,74 años para las mujeres y de 23,98 para los hombres; o, lo que es lo mismo, las primeras se casan un año y un mes más tarde y los segundos un año y cuatro meses más tarde que en 1786 . Esto es, un retraso que concuerda perfectamente con la tendencia al estancamiento de la población que se observa desde mediados de la década de los noventa del siglo xviII. Por lo que respecta a la proporción de casados en el tramo de edades entre los 16 y los 25 años, los resultados de 1804 también apuntan en la misma dirección, representando, para hombres y mujeres respectivamente, un 18,42 y un $34,92 \%$, proporciones inferiores no solo

\footnotetext{
40 El cálculo es representativo, dado que la proporción de viudos en este tramo de edades es irrelevante.

41 Diferencia que se explica parcialmente por la mayor edad masculina al matrimonio.
} 
Tabla 5

Evolución del índice de precocidad nupcial (1768-1786)

\begin{tabular}{|c|c|c|c|c|c|c|}
\hline \multirow{2}{*}{$\begin{array}{l}\text { Dedicación productiva de las } \\
\text { localidades según Cavanilles }\end{array}$} & \multicolumn{2}{|c|}{1768} & \multicolumn{2}{|c|}{1786} & \multicolumn{2}{|c|}{ Diferencia 1768-1786 } \\
\hline & Hombres & Mujeres & Hombres & Mujeres & Hombres & Mujeres \\
\hline Lana & 23,3936 & 36,4722 & 24,382 & 38,093 & $-0,9884$ & $-2,3371$ \\
\hline Lienzo/cáñamo & 24,3354 & 36,7308 & 16,8142 & 31,0938 & 7,5212 & 5,637 \\
\hline Cerámica & 17,0984 & 33,3333 & 14,3548 & 22,6148 & 2,7436 & 10,7185 \\
\hline Otras & 15,9817 & 36,3208 & 20,7317 & 28,3737 & $-4,75$ & 7,947 \\
\hline Sin manufactura & 20,9795 & 34,1478 & 16,3049 & 25,0277 & 4,6745 & 9,1201 \\
\hline Total & 21,8186 & 35,4806 & 19,8841 & 31,7489 & 1,9345 & 3,7317 \\
\hline
\end{tabular}

\section{Producción de paños y nupcialidad}

1000

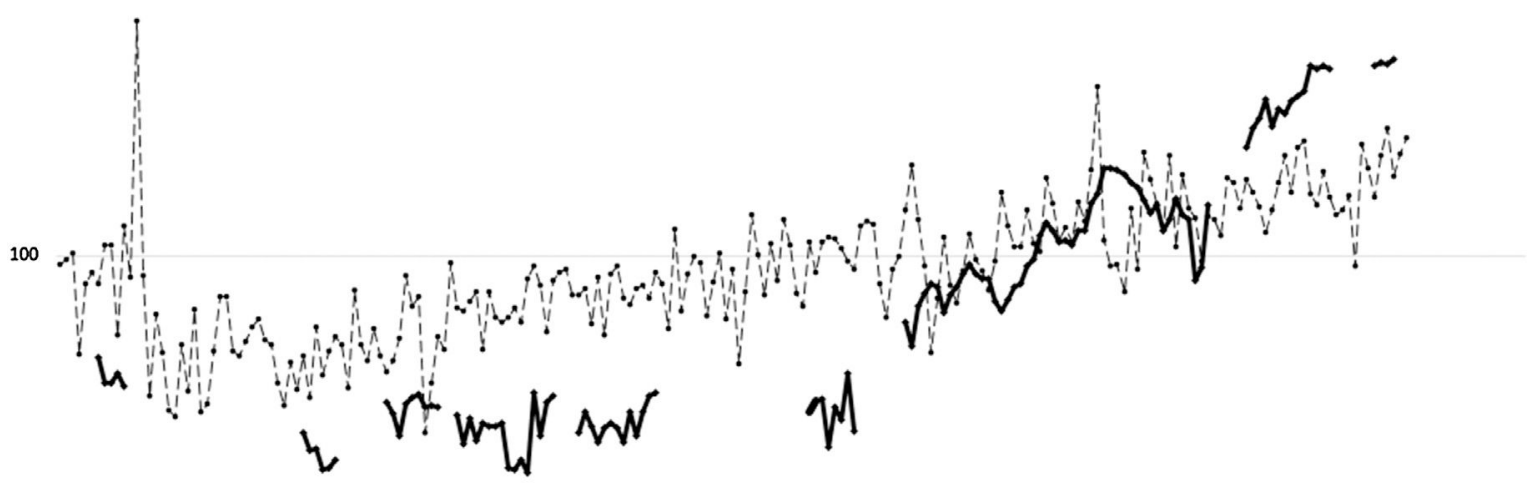

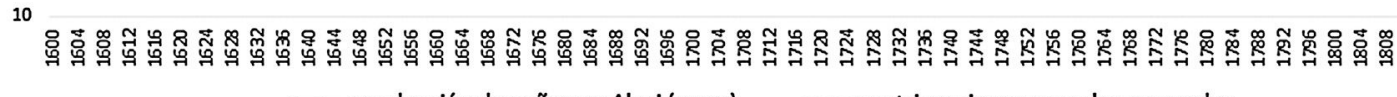

Figura 4. Producción de paños y nupcialidad.

a 1786 sino también a 1768. Dadas las características del censo de 1804 , sin embargo, podemos concluir que los hombres seguramente se casaban un poco más tarde que en 1768 pero las mujeres lo hacían aproximadamente a la misma edad ${ }^{42}$. A partir de 1838 en Penàguila, en cambio, los hombres se casaban más tarde que en 1786 ( 25,3 frente a 23,4 años), pero las mujeres lo hacían claramente antes (22,5 frente a 23,74 años) (Beneito, 1986, p. 166).

Para poder concluir el análisis sería necesario intentar alguna aproximación coyuntural a la relación entre la actividad manufacturera y la nupcialidad. Con este propósito he elaborado la figura 4, en la que se compara la evolución de un índice de la producción de paños en Alcoi $^{43}$ con la serie agregada de matrimonios de la comarca. Se puede comprobar con claridad como a lo largo del sigloxviI y el primer cuarto del XVIII las dos series mantienen comportamientos absolutamente autónomos. Sin embargo, desde los años treinta del Setecientos las curvas muestran un notable paralelismo que se alarga, como

\footnotetext{
42 El tramo de edades de 1804 no es idéntico al de los otros dos sino más amplio: de los 14 a los 25 años.

43 Se trata de un indicador construido a partir de los arrendamientos de la tasa de la bolla que cobraba el gremio de pelaires para su propia financiación por cada pieza fabricada. La metodología empleada en la reconstrucción y un análisis de las limitaciones de la serie en Torró (2000, pp. 252-260 y 775-789.
}

mínimo, durante más de cuarenta años. Aunque, a pesar de las apariencias, los cálculos de correlación indican que el movimiento anual no se corresponde apenas, la coincidencia en el medio plazo resulta suficientemente significativa como para que podamos suponer que existe alguna relación entre ambas variables.

El figura 5 ilustra con mayor detalle esta relación entre la producción de paños en Alcoi -medida en varas castellanas- y los matrimonios de la vecina villa de Cocentaina entre 1746 y 1778 . Aparentemente sigue sin existir correspondencia entre las dos variables -el cálculo de correlación arroja un resultado para $\mathrm{r}$ de 0,1012 y para $r^{2}$ de solo $0,0102-$, pero esta apariencia cambia cuando, en lugar del índice anual, utilizamos medias móviles. En este caso, aunque el coeficiente de correlación sigue ofreciendo valores muy bajos $\left(0,1921\right.$ para $r$ y 0,0369 para $\left.r^{2}\right)$, las curvas que trazan las dos líneas tienden a alinearse. Sin embargo, cabe suponer que la nupcialidad debería correlacionarse con la evolución previa de la demanda de trabajo en función de las necesidades de la producción pañera. De este modo, con el empleo de medias móviles "corridas» - en las que la media de 5 años de matrimonios se correlaciona con la media de los 5 años anteriores de la producción de paños- no solo hay una alineación más clara entre las dos curvas, sino que sus coeficientes de correlación alcanzan valores significativos: 0,438 para r y 0,191 para $\mathrm{r}^{2}$. 
Nupcialidad y producción pañera

Cocentaina (índice de matrimonios) y Alcoi (índice de varas castellanas estimadas), $1746-1778=100$

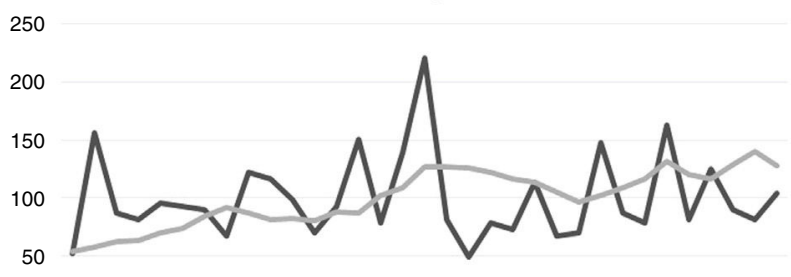

0

17461748175017521754175617581760176217641766176817701772177417761778

Medias móviles (2-1-2)

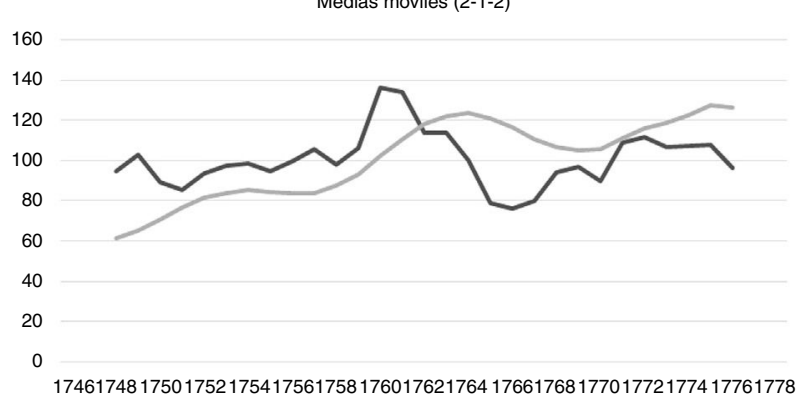

Medias móviles (matrimonios, 4-1; paños, 1-4)

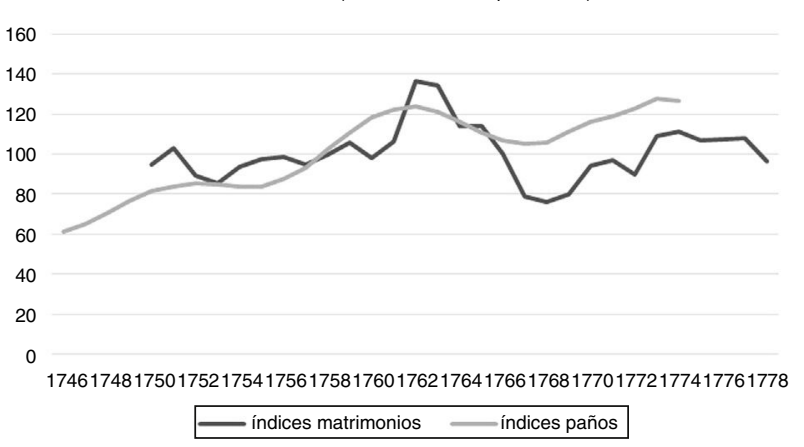

Figura 5. Nupcialidad y producción pañera.

\section{Conclusiones}

La presencia y la progresiva extensión de una importante actividad manufacturera en la comarca parecen haber influido sobre su demografía. Hay suficientes indicios como para sostener la hipótesis de que en el ámbito de influencia de la manufactura alcoyana se confirman, en algunos aspectos destacados, los presupuestos teóricos esbozados por Mendels y Medick sobre la relación entre la protoindustria y el comportamiento demográfico. La manufactura textil -y muy especialmente la pañería-, basada en gran medida en la aportación del trabajo de un considerable y creciente número de familias campesinas, modificó, a lo largo del siglo xviII, los patrones de nupcialidad. En el contexto valenciano de una baja edad al matrimonio -especialmente para las mujeres- pero con cierta tendencia al retraso desde mediados del siglo xviII, las localidades textiles de la zona presentan unos niveles aún más bajos y con tendencia al adelantamiento, hasta la última década del Setecientos.

La evolución demográfica del siglo xviI dependió en gran medida de la dualidad creada por la vitalidad de las parroquias repobladas tras la expulsión de los moriscos, por una parte, y las dificultades de recuperación de las localidades de cristianos viejos, por otra. En esta evolución no parece haber tenido influencia alguna la actividad manufacturera salvo, probablemente, en el caso de Alcoi. Por el contrario, en el siglo XVIII, y coincidiendo con un fuerte período de expansión de la pañería, la nupcialidad mostró un comportamiento coyuntural en el medio plazo, coincidente hasta cierto punto con la evolución de la producción textil lanera de Alcoi.

Aunque no existen por el momento suficientes datos sobre la mortalidad que permitan contrastarlo, la progresiva caída del porcentaje de segundas nupcias -muy inferior en el caso de Penàguila a lo que parece la norma del conjunto del país ${ }^{44}$ - también se corresponde con lo que presuponen las hipótesis de Medick. Este hecho, unido al adelantamiento de la edad al matrimonio, explica la elevada fecundidad que muestran los cocientes matrimoniales. Además, el único factor que, en estas circunstancias, puede ayudarnos a comprender que, a pesar de todo, el crecimiento comarcal -sin Alcoi-fuera inferior al del País Valenciano a lo largo de los dos primeros tercios del siglo xoviII sería una mortalidad infantil y juvenil superior a la media, aunque esto sigue siendo una conjetura. La persistencia de la reducción o un menor retraso de la edad nupcial en la segunda mitad del xviII explican, en cambio, por qué la ralentización del crecimiento que se aprecia para el conjunto valenciano es mucho menos acusada en la comarca. De este modo, recuperó el terreno perdido al crecer durante este período a un ritmo dos veces superior. Lo más probable es que, a pesar del retraso observado en Alcoi a finales del siglo, durante el XIX -como apuntan los datos de Penàguila- la edad nupcial se mantuvo considerablemente más baja que la media, al menos en las localidades vinculadas a la actividad industrial. Estas características, junto a la sospecha de que los movimientos migratorios internos jugaban, en última instancia, un importante papel regulador, aproxima este caso con lo que constata Michael Zell para la región inglesa del Wealden en el siglo $\mathrm{XvI}^{45}$.

A pesar de la acumulación de indicios en la misma dirección, es evidente que el análisis esbozado no prueba nada por sí mismo. En el futuro será necesario establecer claramente las conexiones causales que expliquen estos comportamientos demográficos. La diversidad de situaciones concretas que se ocultan tras las medias obliga, en este sentido, a la prudencia. Es probable, por ejemplo, que la relación tan nítida observada en las localidades de l'Alcoià entre la baja edad al matrimonio de las mujeres y la ocupación industrial que refleja el censo de Floridablanca pueda explicarse por las oportunidades de ocupación femenina que generaba la división sexual del trabajo dentro de la pañería. Como se ha indicado, las operaciones dispersas fuera del núcleo urbano eran, básicamente, el cardado y el hilado. Mientras que la primera es exclusiva de hombres -la documentación habla siempre de tramers o ordimers-, la segunda lo es de mujeres -siempre se habla en este caso de filadores-. Del mismo modo, también parece que el hilado era un trabajo mucho más disperso que el cardado. Así pues, solo un microanálisis que combine el estudio demográfico basado en la reconstrucción de familias, con el conocimiento de la distribución, el mercado y los mecanismos de transmisión de la propiedad de la tierra, y, finalmente, del grado y del tipo de implicación de cada familia o, al menos, de cada localidad, en las actividades manufactureras y/o agrarias, puede dar una respuesta satisfactoria a las cuestiones planteadas. Aunque en el presente trabajo se han propuesto algunas líneas de interpretación, la tarea señalada queda claramente fuera de sus límites, aplazándose para investigaciones futuras.

\section{Agradecimientos}

El autor desea agradecer a los doctores Primitivo J. Pla Alberola, Manuel Ardit Lucas $\dagger$ y Àngel Beneito Lloris el material archivís-

\footnotetext{
44 Cfr. con los datos aportados por Ardit (1993, pp. 59-60).

45 Zell (1994, pp. 52-87). Pat Hudson (1996, pp. 62-63) remarca que es el único trabajo en Inglaterra que aporta pruebas que confirman algunos de los supuestos de las teorías de la protoindustrialización.
} 
tico proporcionado para la elaboración de la presente investigación. Dicho agradecimiento se hace extensivo a Joaquim Cuevas, que leyó y comentó una primera versión del artículo.

\section{Bibliografía}

Aracil, R., García Bonafé, M., 1974. Industrialització al País Valencià (el cas d’Alcoi). Eliseu Climent editor, València.

Ardit, M., 1993. Els homes i la terra del País Valencià, 2 vols. Curial, Barcelona.

Ardit, M., 1996. El siglo xviıI: Demografía y economía. En: Moreno, F. (Ed.), Historia de l'Alcoià, el Comtat y la Foia de Castilla, vol. I. Ed. Prensa Alicantina, Alacant, pp. 385-396.

Ardit, M., 2004. Creixement econòmic i conflicte social. La foia de Llombai entre els segles XIII i XIX. Afers, Catarroja-Barcelona.

Ardit, M., Badenes, M.A., Bernat, J.S., 2001. El País Valencià en el cens d'Aranda (1768). Universitat Jaume I, Castelló.

Badenes, M.A., Bernat, J.S., 1991. Muerte y comportamiento demográfico de los valencianos (siglos XVII-XIX). En: Bernabeu, J. (Ed.), El papel de la mortalidad en la evolución de la población valenciana. Institut de Cultura "Juan Gil-Albert», Alacant, pp. 27-61.

Badenes, M.A., Bernat, J.S., 1994. Crecimiento de la población valenciana (16091857). Alfons el Magnànim, València.

Benaul, J.M., 1991. La indústria tèxtil llanera a Catalunya, 1750-1870. El procés d'industrialització al districte industrial de Sabadell-Terrassa [tesis doctoral en microfichas]. Publicacions de la Universitat Autònoma de Barcelona, Bellaterra.

Beneito, A., 1986. Evolución demográfica de Penàguila: s. XVI al XIX. Investigaciones Geográficas 4, 149-180.

Beneito, A., 1993. Comportamiento epidémico y evolución de las causas de defunción en la comarca de l'Alcoià-Comtat, ss. XIX-XX [tesis doctoral inédita]. Universitat d'Alacant, Alicante (4 vols.).

Beneito, A., 1994. La població d'Alcoi al segle xvin i el cens d'Aranda, any 1768. Alcoi, $118-120$.

Bernabeu, A., Llin, E., 1982. Camperols, menestrals i privilegiats. Ontinyent, 17351802. Ajuntament d'Ontinyent, Ontinyent.

Bevià, P., Giménez, E., Pla, P.J., 1987. El censo de Floridablanca en el estudio de la población valenciana del siglo xviII (comarcas meridionales). En: Chacón, F. (Ed.), La población española en 1787. II Centenario del Censo de Floridablanca, Universidad de Murcia, Murcia, pp. 281-342.

Casey, J., 1981. El regne de València al segle XviI. Curial, Barcelona.

Castelló, J.E., 1976. El País Valenciano en el censo de Floridablanca (1787). Análisis demográfico. Organización y presentación de los datos locales. Alfons el Magnànim, València.

Cavanilles, A.J., 1797. Observaciones sobre la Historia Natural, Geografía, Agricultura, Población y Frutos del Reyno de Valencia [edición facsímil], 2 vols., Madrid.

Chambers, J.D., 1957. The Vale of Trent, 1670-1800: A regional study of economic change. Economic History Review (Suppl 3).

Chayanov, A.V., 1974. La organización de la unidad económica campesina. Nueva Visión, Buenos Aires.

Cuevas, J., 1991. La población valenciana en la Edad Moderna. La Marina en los siglos XVI, XVII y XVIII. Universitat d'Alacant - Institut de Cultura "Juan Gil-Albert», Alacant.

Deasit, M., Seró, J., 1989. El Vapor San Jaime en la industria textil enguerina. Conselleria de Treball i Seguretat Social, València.

Domínguez, R., 1993. Caracterizando al campesinado y a la economía campesina: pluriactividad y dependencia del mercado como nuevos atributos de la "campesinidad». Agricultura y Sociedad 66, 97-136.

Ferrer, L., Gómez, I., Martín, R., Masats, B., Rodríguez, A., Rubí, G., et al., 1992. Edat de casament i celibat definitiu a la Catalunya central (1803-1807). Manuscrits 10, 259-286.

García Sanz, A., 1991. Población e industria textil en una ciudad de Castilla: Segovia, 1530-1750. En: Nadal, J. (Ed.), La evolución demográfica bajo los Austrias. Institut de Cultura "Juan Gil-Albert» - Seminari d'Estudis sobre la Població del País Valencià, Alacant, pp. 153-168.

Goose, N., 2008. Cottage industry, migration, and marriage in nineteenth-century England. Economic History Review 61 (1), 798-819.

Guichard, P., 1976. Al-Andalus: estructura antropológica de una sociedad islámica en occidente. Barral, Barcelona.

Gullickson, G., 1995. Amor y poder en la familia protoindustrial. En: Berg, M. (Ed.), Mercados y manufacturas en Europa. Crítica, Barcelona, pp. 184-209.

Harrison, M., 1981. Chayanov y la economía del campesinado ruso. En: Chayanov, A.V., Kerblay, B., Thorner, D., Harrison, M. (Eds.), Chayanov y la teoría de la economía campesina. Ediciones Pasado y Presente, México.

Hendrickx, F.M.M., 2003. Family, farm, and factory: Labor and the family in the transition from protoindustry to factory industry in 19th-century Twente, the Netherlands. The History Of The Family 8 (19), 45-69.

Henry, L., 1980. Manual de demografía histórica. Técnicas de análisis. Crítica, Barcelona.

Hernández R. (2003). La industria textil rural en Castilla: Astudillo, 1750-1936 [tesis doctoral]. Universidad de Valladolid [consultado 22 Ene 2017]. Disponible en: http://www.cervantesvirtual.com/descargaPdf/la-industria-textilrural-en-castilla-astudillo-17501936-0/.

Hernández, R., 2008. Demografía e industria: algunas aplicaciones metodológicas del Catastro de la Ensenada para el estudio de la industria textil castellana. Revista de Demografía Histórica 27 (2), 187-217.
Hernández Marco, J.L., 1980. Estructura económica e industrialización. Enguera y Bocairent durante los siglos XVIII y XIX [tesis doctoral inédita]. Universitat de València, Valencia (dos vols.).

Hudson, P., 1996. Proto-industrialization in England. En: Ogilvie, S.C., Cerman, M. (Eds.), European Proto-Industrialization. Cambridge University Press, pp. 49-66.

Hudson, P., King, S., 2000. Two textile townships, c 1660-1820: A comparative demographic analysis. Economic History Review 53 (4), 706-741.

Knotter, A., 2001. Problems of the 'family econmy': Peasant economy domestic production and labour markets in pre-industrial Europe. En: Prak, M. (Ed.), Early Modern Capitalism. Economic and Social Change in Europe, 1400-1800. Routledge, London.

Kriedte, P., Medick, H., Schlumbohm, J., 1986. Industrialización antes de la industrialización. Crítica, Barcelona.

Kriedte, P., Medick, H., Schlumbohm, J., 1993. Proto-industrialization revisited: Demography, social structure and modern domestic industry. Continuity and Change 8 (2), 217-252.

Kriedte, P., Medick, H., Schlumbohm, J., 1996. Proto-industrialisation: Bilan et perspectives. Démographie structure sociale et industrie à domicile moderne. En: Leboutte, R. (Ed.), Proto-industrialisation. Recherches récentes et nouvelles perspectives. Librairie Droz, Genève, pp. 28-71.

Laslett, P., 1987. El mundo que hemos perdido explorado de nuevo. Madrid, Alianza.

Laslett, P., Wall, R. (Eds.), 1972. Household and Family in Past Time, Cambridge University Press.

Levine, D., 1976. The demographic implications of rural industrialization: A family reconstitution study of Shepshed. Leicestershire, 1600-1851. Social History 1 (2), 177-196.

Levine, D., 1977. Family Formation in an Age of Nascent Capitalism. Academic Press, New York.

Levine, D., 1987. Reproducing Families: The Political Economy of English Population History. Cambridge University Press.

Levine, D., 1996. Asymmetrical non-linear population dynamics. En: Leboutte, R. (Ed.), Proto-industrialisation. Recherches récentes et nouvelles perspectives. Librairie Droz, Genève, pp. 93-106.

Llopis, E., 1993. La formación del 'desierto manufacturero’ extremeño: el declive de la pañería tradicional al final del Antiguo Régimen. Revista de Historia Industrial 3, 41-64.

Marfany, J., 2005. Las crisis de mortalidad en una comunidad catalana, Igualada, 1680-1819. Revista de Demografía Histórica 23, 13-42.

Marfany, J., 2006. Choices and constraints: Marriage and inheritance in eighteenthand early-nineteenth-century Catalonia. Continity and Change 21 (1), 73-1906, http://dx.doi.org/10.1017/S0268416006005789

Marfany, J., 2010. Is it helpful to talk about proto-industrialization? Some suggestions from a Catalan case study. Economic History Review 63 (4), 942-973.

Marfany, J., 2012. Land, Proto-industry and Population in Catalonia, c 1680-1829. An Alternative Transition to Capitalism? Ashgate, Farnham, UK.

Martini, M., Bellavitis, A., 2014. Household economies, social norms and practices of unpaid market work in Europe from the sixteenth century to the present. The History of Family 19, 273-282.

Medick, H., 1976. The proto-industrial family economy: The structural function of household and family during the transition from peasant society to industrial capitalism. Social History 1 (3), 291-315, doi: 0.1080/03071027608567380.

Mendels, F.F., 1984. Niveau des salaires et âge au marriage en Flandre, Xviıè-XvıIIè siècles. Annales. E.S.C. 39 (5), 939-955.

Ogilvie, S.C., 1997. State Corporatism and Proto-Industry. The Württemberg Black Forest 1580-1797. Cambridge University Press.

Ogilvie, S.C., 1996. The theories of proto-industrialization. En: Ogilvie, S.C., Cerman, M. (Eds.), European Proto-Industrialization. Cambridge University Press, pp. $1-11$.

Ogilvie, S.C., 2003. A Bitter Living: Women, Markets and Social Capital in Early Modern Germany. Oxford University Press.

Ogilvie, S.C., 2008. Protoindustrialization. En: Durlaf, S.N., Blume, L.E. (Eds.), The New Palgrave Dictionary of Economics. , 2nd edition. The New Palgrave Dictionary of Economics Online. Palgrave Macmillan, http://dx.doi.org/10.1057/ 9780230226203.1357 [consultado 20 Ene 2017]. Disponible en: http://www. dictionaryofeconomics.com/article?id=pde2008_P000341

Pérez García, J., Ardit, M., 1988. Bases del crecimiento de la población valenciana en la Edad Moderna. En: Varios autores (Ed.), Estudis sobre la població al País Valencià, I. Alfons el Magnànim - Institut de Cultura "Juan Gil-Albert», València, pp. 35-69.

Pérez Moreda, V., Reher, D.S., 2003. Hacia una definición de la demografía urbana: España en 1787. Revista de Demografía Histórica 21 (1), 113-140.

Pérez Planelles F. (1807). Plan Estatístico de la villa de Alcoy [Manuscrit] (edición facsímil e introducción a cargo de Ismael Vallès, Ajuntament d'Alcoi/Secció de Geografia de la Universitat de València, 1983).

Pfister, U., 1992. The protoindustrial household economy: Toward a formal analysis. Journal of Family History 17 (2), 201-232.

Pla, P., 1983. La población del Marquesado de Guadalest en el siglo xviI. Instituto de Estudios Alicantinos, Alacant.

Pla, P., 1986. La población alicantina en los siglos xVI al xVIII. En: Mestre, A. (Ed.), Historia de la provincia de Alicante, IV. Ediciones Mediterráneo, Murcia, pp. $17-70$.

Pla, P., 1988. Los movimientos migratorios en el condado de Cocentaina tras la expulsión de los moriscos. En: Varios autores (Ed.), Estudis sobre la població al País Valencià, I. Alfons el Magnànim - Institut de Cultura "Juan Gil-Albert», València, pp. 301-314. 
Pla, P., 1991. Despoblación y repoblación. La crisis del xviı en el Cuartel de La Marina y Las Montañas. En: Nadal, J. (Ed.), La evolución demográfica bajo los Austrias. Institut de Cultura "Juan Gil-Albert» - Seminari d’Estudis sobre la Població del País Valencià, Alacant, pp. 195-239.

Ros, R., 1999. La industria textil lanera de Béjar (1680-1850). La formación de un enclave industrial. Junta de Castilla y León. Consejería de Educación y Cultura, Valladolid.

Santacreu, J.M., 1985. Estudios sobre el siglo Xvin en la villa de Agres. En: Varios autores (Ed.), Miscelánea histórica de Agres. C.A.A.M., Alacant, pp. 89-120.

Sarasúa, C., 2000. El análisis histórico del trabajo agrario: cuestiones recientes. Historia Agraria 22, 79-96.

Seccombe, W., 1992. A Millenium of Family Change. Feudalism to Capitalism in Northwestern Europe. Verso, London.

Terol, V., 1996. La indústria sabonera a Albaida, segles XVII-XIX. En: Varios autores (Ed.), Cultura material i canvi social. Actes del Segon Congrés d'Arqueologia Industrial del País Valencià. Associació Valenciana d'Arqueologia Industrial, València, pp. 157-169.

Terol, V., 2002. Un regne sense cavallers? La Germania a la sotsgovernació de Xàtiva [tesis doctoral inèdita]. Universitat de València, València.

Torrents, A., 1993. Transformacions demogràfiques en un municipi industrial català: Sant Pere de Riudebitlles, 1608-1935 [tesis doctoral inédita]. Universitat de Barcelona, Barcelona.

Torró, L., 1994. Sobre la proto-industrialització. Reflexions a partir d'un cas local: Alcoi (ss. XVI-XIX). Afers. Fulls de Recerca i Pensament 19, 659-680.

Torró, L., 1996a. La Reial Fàbrica de Draps d'Alcoi. Ordenances gremials (segles XVI al xvirI). Ajuntament d'Alcoi - Institut de Cultura "Juan Gil-Albert», Alcoi.

Torró, L., 1996b. Als voltants dels orígens de la industrialització valenciana. En: Azagra, J., Mateu, E., Vidal, J. (Eds.), De la sociedad tradicional a la economía moderna. Estudios de Historia Valenciana Contemporánea - Institut de Cultura "Juan Gil-Albert», pp. 34-61.

Torró, L., 2000. Proto-indústria i acumulació originària de capital a la vila valenciana d'Alcoi (1430-1823) [tesis doctoral inédita]. Universitat d'Alacant, Alacant.
Torró, L., 2008. Fiscalidad, manufactura y actividad agraria en la época moderna un caso local (Alcoi, 1444-1816). En: Vallejo, R. (Ed.), Los tributos de la tierra. Fiscalidad y agricultura (siglos XII-Xx). Publicacions de laUniversitat de València, València, pp. 389-410.

Torró Abad, J., 2009. Formas de poblamiento y urbanismo. Cómo se organizaron los lugares de habitación de los musulmanes del reino de Valencia (siglos XIII-XVI) En: Benítez, R., García Marsilla, J.V.(Eds.), Entre tierra y fe. Los musulmanes en el reino cristiano de Valencia (1238-1609). Universitat de València, València, pp. 201-217.

Vallès, I., 1986. Indústria tèxtil i societat a la regió Alcoi-Ontinyent, 1780-1930. Universitat de València, València.

Vandenbroeke, C., 1984. Le cas flamand: évolution sociale et comportements démographiques aux xvirè-Xıxè siècles. Annales. E.S.C. 39 (5) 915-938.

Vandenbroeke, C., 1996. Proto-industry in Flanders: A critical review. En: Ogilvie, S.C., Cerman, M. (Eds.), European Proto-Industrialization. Cambridge University Press, pp. 102-117.

Van Zanden, J.L., 2011. The Malthusian intermezzo: Women's wages and human capital formation between the late Middle Ages and the demographic transition of the 19th century. The History of Family 16, 331-342.

Wrightson, K., Levine, D., 1995. Poverty and Piety in an English Village, Terling, 1525 1700. Clarendon Press, Oxford.

Wrigley, E.J., 1985. Historia y población. Introducción a la demografía histórica. Crítica, Barcelona.

Yanini, A., 1977. La industria textil en Onteniente. Estudis d'Història Contemporània del País Valencià, pp. 103-117.

Zell, M., 1994. Industry in the countryside. Wealden society in the sixteenth century. Cambridge University Press.

Zomeño, A., 2011. Sociedad, familias e individuos en al-Andalus. En: Chacón, F., Bestard, J. (Eds.), Familias. Historia de la sociedad española (del final de la Edad Media a nuestros días). Cátedra, Madrid, pp. 35-80. 